\title{
La secularización de los ritos fúnebres en el catolicismo popular: Bogotá (Colombia)*
}

\author{
DOI: https://doi.org/10.18046/recs.i33.4027 \\ The Secularization of Funeral Rites in Popular
Catholicism: Bogotá, Colombia \\ William Mauricio Beltrán ${ }^{* *}$ \\ Universidad Nacional de Colombia (Bogotá, Colombia) \\ Nicolás Medina-Morales ${ }^{* * *}$ \\ Universidad Nacional de Colombia (Bogotá, Colombia) \\ Yenny Roberto ${ }^{* * * *}$ \\ Universidad Nacional de Colombia (Bogotá, Colombia)
}

\begin{abstract}
* El presente artículo es el resultado final de un proyecto de investigación realizado durante los años 2017 y 2019, financiado por la Universidad Nacional de Colombia (Colombia). Artículo de investigación recibido el 13.05.2020 y aceptado el 03.01.2021.

** Sociólogo y magíster en Sociología de la Universidad Nacional de Colombia (Colombia), y Doctor en Étude des Sociétés Latino-Américaines de la Universidad Paris III Sorbonne Nouvelle (Francia). Actualmente, se desempeña como profesor asociado del Departamento de Sociología de la Universidad Nacional de Colombia (Colombia). Correo electrónico: wmbeltranc@unal.edu.co ORCID: https://orcid.org/0000-0001-7075-3081

*** Sociólogo de la Universidad Nacional de Colombia (Colombia) y estudiante de la Maestría en Comunicación y Medios de la misma universidad. Correo electrónico: nimedinamo@unal.edu.co ORCID: https://orcid.org/00000002-8311-6046

**** Socióloga de la Universidad Nacional de Colombia (Colombia) y estudiante de Psicología de la misma universidad. Correo electrónico: ykrobertog@unal.edu.co ORCID: https://orcid.org/0000-0001-6229-1892
\end{abstract}




\section{Cómo citar/How to cite}

Beltrán, William Mauricio; Medina-Morales, Nicolás; Roberto, Yenny (2021). La secularización de los ritos fúnebres en el catolicismo popular: Bogotá (Colombia). Revista CS, 33, 141-170.

https://doi.org/10.18046/recs.i33.4027 


\section{Resumen}

Desde la Colonia, los bogotanos han despedido a sus seres amados siguiendo las orientaciones de la Iglesia católica, y guiándose por las creencias y costumbres propias del catolicismo popular. Sin embargo, desde mediados del siglo XX, entre los católicos bogotanos los ritos fúnebres se han venido transformando. Este cambio es analizado aquí con la ayuda del concepto de secularización, entendido como un proceso multidimensional y de larga duración. Gracias a un análisis sociohistórico, se identifican algunos factores que han permitido la secularización de los ritos fúnebres, es decir, su progresiva liberación del control y regulación de la Iglesia católica. Se destacan al respecto tres procesos fundamentales: 1) la regulación del rito por parte del Estado; 2) el ascenso de las empresas funerarias; y 3) la globalización de las comunicaciones, particularmente, la masificación de las redes sociales que se conectan gracias a internet.

\section{PALABRAS CLAVE:}

secularización, catolicismo popular, ritos fúnebres, Iglesia católica, empresas funerarias

Since the Spanish colonization, the inhabitants of Bogotá have bid farewell to their loved ones following the instructions of the Catholic Church and are guided by the beliefs and customs of popular Catholicism. However, since the mid-twentieth century, funerary rites have been transformed among Bogotá's Catholics. This change is analyzed in this article with the help of the concept of Secularization; understood as a multidimensional, longterm process. Thanks to socio-historical analysis, this paper identifies several factors that have engendered the secularization of the funeral rite: its progressive liberation from the control and regulation of the Catholic Church. Three fundamental processes stand out in this regard: 1) the regulation of the rite by the State; 2 ) the rise of funeral companies; 3) the globalization of communications, particularly the massification of the so-called social networks that are connected thanks to the internet.

\section{KEYWORDS:}

Secularization, Popular Catholicism, Funerary Rites, Catholic Church, Funeral Company 



\section{Introducción}

En las sociedades occidentales contemporáneas, los ritos fúnebres mantienen su lugar entre los ritos más sagrados. Hasta hoy, con muy raras excepciones, tienen un carácter religioso y son presididos por administradores de los bienes simbólicos de salvación (por ejemplo, sacerdotes, pastores o rabinos). A pesar de esto, se defiende aquí una tesis que para algunos puede parecer problemática: ni siquiera los ritos fúnebres escapan al proceso de secularización que se está dando en las sociedades occidentales y, en particular, en la colombiana. Esta afirmación nos obliga a una aclaración conceptual: ¿qué entendemos por secularización?

Durante la mayor parte del siglo XX, en las ciencias sociales, se asoció la secularización con una relación causal entre el avance de la modernidad y la erosión progresiva de las instituciones y las creencias religiosas (Berger, 2006) o, por lo menos, con el confinamiento de la experiencia religiosa al ámbito propio de la vida privada (Luckmann, 1967). Sin embargo, en diversas regiones del planeta, particularmente en América Latina, la modernidad o, más bien, las modernidades, más que la erosión de las creencias religiosas ha traído consigo un proceso de pluralización, mutación y recomposición religiosa (Bastian, 1997; Mallimaci, 2017; Martin, 2002; 2005; Morello, 2017). Esta situación obligó a la revisión de los postulados clásicos sobre la secularización, y desembocó en una redefinición del concepto mismo (Davie, 2011).

Entendemos aquí la secularización como un proceso multidimensional y de larga duración (Tschannen, 1992). Coincidimos con Casanova (2012), Dobbelaere (1981) y Tschannen (1992) en que, entre las diversas dimensiones de la secularización, la diferenciación y autonomización de las esferas institucionales constituyen su aspecto primordial. Ambos procesos permiten a las diferentes esferas sociales, por ejemplo, a las instituciones políticas, económicas, educativas y culturales, independizarse y adquirir una dinámica y una racionalidad propia en el seno de una sociedad determinada. Esto implica que cada una de estas esferas se libera progresivamente del control y tutela que sobre ellas ejercía la institución religiosa históricamente dominante.

En el caso colombiano, lo ya señalado nos permite definir la secularización de los ritos fúnebres como un proceso de larga duración, en el que la Iglesia católica y sus sacerdotes han ido perdiendo progresivamente legitimidad en lo concerniente a la definición de la forma y significado de los mismos. Aunque la secularización de los ritos fúnebres parece ser una tendencia general en las sociedades cristianas occidentales, la información empírica que aquí se presenta intenta describir este proceso en el seno del catolicismo popular colombiano.

Según la definición de Marzal (2002: 315), el catolicismo popular es "la forma en que se expresan religiosamente, para dar un sentido trascendente a su vida, las 
grandes mayorías del pueblo de América Latina, que se definen a sí mismas como católicas, a pesar de su escaso cultivo religioso". Según esta definición, los católicos populares no son necesariamente pobres, en lo referido a sus condiciones económicas, sino creyentes con un "escaso cultivo religioso" (Marzal, 2002:315). No nos acercamos de manera acrítica a la definición de catolicismo popular, sino que acudimos a ella para abarcar una gran diversidad en el seno del catolicismo latinoamericano (Mallimaci, 2017; Parker, 1996; Roux, 2017), diversidad que está enriquecida por factores regionales y étnicos, y que permite fecundas posibilidades de hibridación religiosa (García-Canclini, 1989), construcción de sentido y vida comunitaria. Tampoco le otorgamos al catolicismo popular una connotación negativa o peyorativa, como cuando, por ejemplo, se le asocia con una religión inferior, impura o alienante.

Cuando nos referimos al catolicismo popular, intentamos generalizar en torno a la experiencia religiosa de la mayoría de los católicos latinoamericanos, experiencia que no se define desde arriba, es decir, desde la erudición de los teólogos, sino desde la cotidianidad de las prácticas, de las creencias y de las expectativas de los fieles (Morello, 2017). En el catolicismo popular se imponen, como bien lo muestra Marzal (2002), las necesidades inmediatas de los fieles. En el caso que nos ocupa, la necesidad de buscar sosiego para calmar el dolor que causa la pérdida de un ser amado, o esperanza frente a las incertidumbres del más allá.

En el catolicismo popular, el doliente es el actor principal del rito fúnebre, participa en él motivado por el vínculo afectivo que lo unía al difunto y que ahora lo une a su memoria y a los símbolos que lo representan. Sus decisiones y compromiso con respecto al rito fúnebre están en buena medida motivados por su propio bienestar (ponerse en paz con el difunto), o por la búsqueda del bienestar del alma del difunto en el más allá (ayudarle a encontrar el descanso eterno). Para el doliente, la mejor evidencia de que el rito fúnebre ha sido celebrado de manera adecuada es de tipo emocional, se expresa en la satisfacción de haber dado a su difunto la despedida que este merece, y en la tranquilidad que proviene de la creencia según la cual la adecuada celebración del rito le permite al alma del difunto descansar en paz (Collins, 2009; Strauss; Corbin, 2002).

Desde diversas perspectivas sociológicas, como la sociología comprensiva y el interaccionismo simbólico, el difunto ya no es un actor social, pero sus restos (cuerpo, tumba, cenizas) constituyen los símbolos más importantes del rito fúnebre (Collins, 2009). Para el doliente, los restos fúnebres son símbolos sagrados en todo el sentido de esta expresión (Durkheim, 1982; Eliade, 1998), no se puede siquiera imaginar la posibilidad de jugar o bromear con ellos' ${ }^{1}$. En el catolicismo popular, el trato inade-

1. Para simplificar el lenguaje, el conjunto de símbolos que representan al difunto será denominado, en adelante, restos fúnebres. 
cuado de los restos fúnebres constituye una profanación con consecuencias graves, tanto para el alma del difunto como para el responsable de la profanación.

Según los testimonios de los entrevistados, el trato que los dolientes dan a los restos fúnebres tiene consecuencias que afectan al difunto en el más allá. Puesto que, para el católico, la salvación del alma constituye el bien supremo, los dolientes, especialmente los más vinculados emocionalmente con el difunto, no escatiman energías ni recursos materiales para asegurarse de que el rito se celebre de la manera adecuada. Sin embargo, al doliente no solo le interesa el bienestar del difunto o la salvación de su alma, sino que también actúa motivado por sus propios intereses y bienestar. En el catolicismo popular, las almas de los difuntos son tratadas como entidades que siguen actuando desde el más allá, y que pueden ser manipuladas para que intervengan en beneficio de los dolientes. Así, por medio de determinados ritos, los creyentes pueden hacerse merecedores del afecto y el favor de entidades como "las almas benditas" o "almas del purgatorio" (Villa-Posse, 1993: 87, 128).

En este mismo sentido, los ritos fúnebres permiten a los dolientes pagar deudas pendientes con el difunto y evitar su posible ira (que regrese del más allá a cobrarlas). En el catolicismo popular, esta creencia implica que el rito fúnebre debe realizarse bajo la consideración de poner en paz al doliente y al difunto, para esto es de vital importancia complacer los últimos deseos o la última voluntad del fallecido. Así, en un sentido amplio, los ritos fúnebres son también ritos de duelo: su adecuada ejecución facilita a los dolientes enfrentar y superar el sufrimiento propio de la pérdida. En palabras de Pochintesta (2016:37), estos ritos “ofrecen una mediación terapéutica para los deudos frente al desorden que la muerte provoca". Sin embargo, esto solo es posible con el apoyo de una comunidad (Thomas, 1985).

En el caso colombiano, tres actores adicionales intervienen en la definición del rito fúnebre y en el mantenimiento de su legitimidad: 1) la Iglesia católica, que por medio de sus sacerdotes administra los bienes simbólicos de salvación entre los que se encuentran los ritos fúnebres, pues en la medida en que el católico popular reconoce la legitimidad de la Iglesia y sus sacerdotes, solicita la mediación del sacerdote y toma en cuenta sus orientaciones para la apropiada ejecución del rito;2) el Estado, que, en ejercicio de su autoridad legal-burocrática y por razones relacionadas con el interés general, ha venido introduciendo regulaciones en lo relacionado con el tratamiento que debe darse a los restos fúnebres; y 3) los empresarios de los ritos fúnebres que, por medio de su oferta de servicios y en el contexto de la celebración de contratos comerciales, introducen regulaciones en lo relacionado con el rito y el manejo de los restos fúnebres. Cuando hablamos de regulaciones nos referimos a que estos tres actores imponen a los dolientes determinadas reglas que definen la 
ejecución legítima del rito y que incluyen distinciones con respecto a lo apropiado o permitido, y lo inapropiado o prohibido.

Estas aclaraciones nos permiten formular nuestra principal hipótesis de trabajo: en Colombia, la Iglesia católica, que era dominante en la definición legítima del rito fúnebre, ha ido perdiendo la legitimidad que le está siendo disputada por los demás actores que participan en él. En otras palabras, en la medida en que la autoridad de la Iglesia católica es cuestionada, la legitimidad de la autoridad del Estado, de los empresarios del rito fúnebre y del doliente (como actor individual) se fortalecen. Por lo tanto, incluso entre los católicos, los ritos fúnebres se vienen autonomizando de la tutoría de la Iglesia. Es a este proceso al que denominamos secularización de los ritos fúnebres.

La presente investigación tiene como objetivo principal identificar algunos factores históricos que, en Colombia, especialmente en la ciudad de Bogotá, han permitido este proceso. Esta delimitación se concibió asumiendo que el proceso de secularización de la sociedad colombiana es un fenómeno más fácil de observar en las grandes urbes, y que se ha acelerado en las últimas décadas, favorecido por factores como: la explosión demográfica, la industrialización, la apertura a los mercados internacionales, la rápida urbanización y una creciente influencia cultural de los medios masivos de comunicación. Todos estos elementos han facilitado la autonomización de las esferas institucionales y la desmonopolización de los bienes simbólicos de salvación, administrados tradicionalmente por la Iglesia católica (Beltrán, 2013).

En Colombia, no son numerosas las investigaciones que se ocupan de las transformaciones recientes de los ritos fúnebres. Entre ellas se destacan las de Villa Pose (1993; 2002), que observan este proceso a finales del siglo XX, estudiando aspectos que se relacionan con la presente investigación. Por ejemplo, se menciona que la industrialización, el crecimiento de las ciudades y la consolidación de las funerarias son aspectos que han modificado la manera como se celebra el rito y se vive el duelo, y que, por lo tanto, han contribuido a socavar las tradiciones católicas.

En América Latina, se pueden rastrear más investigaciones al respecto. Se destacan las realizadas por León (1997), en Santiago de Chile, y Pochintesta (2016), en la ciudad de Buenos Aires. Esta última es la que más coincidencias tiene con la presente investigación, puesto que, basada en entrevistas biográficas, muestra cómo las nuevas generaciones prefieren la cremación al enterramiento, mientras que los adultos mayores siguen valorando la inhumación y el cementerio, lo que además significa que los jóvenes y los adultos mayores se relacionan de manera diferente con los muertos.

Por último, y en un nivel más global, las investigaciones de Gamba (2017a; 2017b) representan un aporte para la comprensión de las transformaciones recientes de los ritos fúnebres. Estas muestran el papel que están desempeñando las nuevas tecno- 
logías y, en particular, la generalización de internet y de plataformas tecnológicas. como las redes sociales, en los cambios recientes de los ritos fúnebres y en la manera como las nuevas generaciones se relacionan con la muerte. Según este autor, el uso de internet ofrece nuevos dispositivos de memoria para recordar a los difuntos, provee de nuevos medios para la comunicación de los vivos y los muertos, y permite que la muerte adquiera nuevos significados. Sin embargo, ninguna de las investigaciones mencionadas analiza la trasformación de los ritos fúnebres valiéndose de la teoría de la secularización. Es en este aspecto en el que la presente investigación pretende ofrecer un aporte.

Por otro lado, en Colombia se han adelantado algunas investigaciones que se acercan al tema del presente artículo en tanto se ocupan de instituciones relacionadas con la muerte. Especialmente, encontramos valiosos estudios que, desde una perspectiva histórica, se ocupan del proceso de secularización de los cementerios. A saber, del proceso en que estos han dejado de ser administrados por la Iglesia católica, para quedar en manos de los gobiernos locales o de las empresas funerarias, un proceso que, en el caso de Colombia, inició muy temprano en el siglo XIX, y que ha estado acompañado por tensiones y conflictos entre actores religioso y seculares. Sobre este tema, se pueden consultar, por ejemplo, las investigaciones de Calvo (1998), Escovar, (2002), Molina (2013) y Ortega Ricaurte (1931). Ahora bien, a pesar de ser un asunto que, sin duda, se relaciona con el del presente estudio, hemos decidido no adentrarnos en su comprensión histórica, bajo la consideración de que, por su envergadura y complejidad, la visión del proceso de secularización de los cementerios constituye en sí misma un capítulo del proceso de la secularización en Colombia que merece ser investigado a profundidad.

Otro tema que ha sido estudiado en el país, y que se relaciona con el que aquí abordamos, es la evolución de las empresas funerarias y de los servicios que estas ofrecen. La mayoría de las investigaciones que se ocupan de este asunto no provienen de las ciencias sociales, sino de la mercadotecnia y la administración de empresas. Estas se interesan, sobre todo, por analizar la viabilidad económica de dichas empresas y de los servicios que ofrecen. Al respecto, se pueden consultar las investigaciones de Bedoya (2015), Orozco Girón (2019) y las publicaciones de la Red Funeraria (Funerarias colombianas, 2015). Sin embargo, puesto que en Colombia el ascenso de las empresas funerarias ha sido decisivo en el quiebre del monopolio de la administración de los ritos fúnebres que mantenía la Iglesia católica, estas investigaciones son citadas y comentadas en el apartado del artículo dedicado a las empresas funerarias.

Para alcanzar los objetivos de la investigación, aplicamos un diseño metodológico hermenéutico. La construcción del conocimiento estuvo orientada por el medio y 
el fin principales que Max Weber (2014) ha fijado para la sociología comprensiva, a saber: la comprensión del sentido subjetivo de la acción social mediante actos interpretativos, pero este principio weberiano solo fue tomado como fundamento general del diseño metodológico. La lógica que orientó la construcción del conocimiento estuvo delimitada, de manera más precisa, por la propuesta metodológica que Giddens ha denominado "doble hermenéutica". Según esta perspectiva, el proceso de construcción de conocimiento de las ciencias sociales acontece por la intersección de dos operaciones hermenéuticas: por un lado, las operaciones de interpretación y comprensión del mundo sociocultural de los actores sociales (primera hermenéutica) y, por otro, la interpretación de los procesos sociales efectuados en los metalenguajes de los científicos sociales (segunda hermenéutica) (Giddens, 1993:396).

La intersección de estas dos operaciones hermenéuticas genera un diálogo constante entre los marcos de sentido que cada una produce y, consecuentemente, un enriquecimiento del conocimiento. En ese sentido, el diseño metodológico de la investigación se propone recoger las narrativas de sentido de los actores sociales y reinterpretarlas con base en los elementos conceptuales de la tesis sobre secularización. En otras palabras, el trabajo consiste en incluir un proceso social específico (la transformación de los ritos fúnebres) en un contexto social más amplio (el proceso de secularización), para así explicarlo causalmente en su desarrollo.

La manera como los actores sociales comprenden el sentido del proceso de transformación de los ritos fúnebres fue captada mediante tres técnicas de recolección de datos: 1) revisión de documentos legales y de prensa relacionados con los cambios normativos que regulan los rituales fúnebres en el período analizado; 2) revisión de páginas web y otros documentos disponibles en internet que informen sobre los servicios y la evolución de las empresas funerarias que funcionan en la ciudad; y 3 ) entrevistas a profundidad a católicos populares de Bogotá.

Solo se realizaron 13 entrevistas, ya que el punto de saturación se alcanzó rápidamente. En otras palabras, los últimos entrevistados añadieron poca información, pero confirmaron la que habían suministrado los primeros. La muestra se construyó a conveniencia, con la estrategia de bola de nieve para la ubicación de los informantes. Se entrevistaron 7 mujeres y 6 hombres. La muestra privilegió la variable etaria, incluyendo a personas de dos grupos de edad: el primero en un rango de 20-30 años ( 5 entrevistados), y el segundo en uno de mayores de 65 años (8 entrevistados); esto con la intención de poder rastrear el cambio de los ritos fúnebres desde una perspectiva generacional. La información suministrada por los entrevistados se analizó siguiendo las orientaciones metodológicas de Strauss y Corbin (2002), y con los debidos protocolos de anonimato y de consentimiento informado. 
El trabajo metodológico consistió en reinterpretar los datos acopiados mediante las técnicas ya mencionadas, tomando como esquema de referencia los elementos conceptuales de la tesis sobre la secularización para, de este modo, construir una imagen más o menos adecuada de la totalidad del proceso social y presentarla en una narrativa científica.

Es posible que el lector perciba en el relato un sentimiento de añoranza o incluso de nostalgia por la manera en que antaño se celebraban los ritos fúnebres, y por la solemnidad y sacralidad que los acompañaban. Esta nostalgia no es tanto el reflejo de los sentimientos de los autores, sino, más bien, el eco de los sentimientos de los entrevistados, ya que en particular los de mayor edad recuerdan los viejos tiempos como mejores, tanto porque los funerales se contaban entre los ritos más solemnes, y en ellos se actualizaban y reforzaban los lazos comunitarios, como porque, además, las preguntas por los ritos fúnebres les permiten recordar una época en la que la otra vida importaba más que esta, y en la que los muertos exigían más respeto que los vivos.

\section{Los ritos fúnebres en el catolicismo popular}

En Bogotá, todavía en la década de 1980, era común que el velorio católico se realizara en espacios privados e íntimos ${ }^{2}$, generalmente en la misma casa donde habitaba el difunto en el momento de su muerte. "Se velaba a los muertos en sus viviendas, donde parientes, amigos, vecinos y conocidos iban a saludar a los deudos, a 'despedirse' del difunto y a acompañar por un rato a la familia" (Villa-Posse, 2002: 10-12), costumbre que también está documentada para otras ciudades de América Latina (León, 1997; Orozco-Girón, 2019; Pochintesta, 2016).

Los dolientes, por lo general los más cercanos al difunto, se encargaban de la adecuación y el ornato de la habitación en donde se realizaba el velorio. Esto, generalmente, implicaba decorarla con símbolos religiosos (crucifijos, o cuadros de santos o vírgenes de la tradición católica). Del mismo modo, se ocupaban de la preparación del cuerpo (lavarlo, peinarlo, afeitarlo y vestirlo). Mientras se compraba el ataúd (de cuya distribución se encargaban locales comerciales), el cuerpo reposaba en una mesa, acompañado de hierbas aromáticas. En palabras de una entrevistada:

2. Se entiende aquí el velorio como un rito católico celebrado por parientes, amigos y allegados del difunto, que consiste en acompañar los restos fúnebres por un período que generalmente se extiende por varios días y sus noches, antes de ser sepultado o cremado. Este ritual está acompañado por la repetición de ciertas oraciones, y constituye también un espacio para expresar las condolencias y otros gestos de solidaridad a los dolientes. 
"se velaba toda la noche". Por lo cual, los dolientes se turnaban "para no dejar solo el cuerpo" (mujer de 74 años, comunicación personal, 05.10.2017).

El velorio constituía un rito de comensalidad. Los parientes más cercanos al difunto se sentían en la obligación de ofrecer alimentos y bebidas (especialmente café y bebidas alcohólicas) a todos aquellos que los acompañaban en el rito. Durante el velorio, se repetían oraciones, especialmente se rezaba el rosario con la dirección de un miembro de la comunidad (mujer de 78 años, comunicación personal, 02.11.2017). Además, a través de los gestos y comentarios, los dolientes exaltaban las virtudes del difunto, le ofrecían respeto y honraban su memoria, en una costumbre que Perrot define como honorabilidad post mortem. En el catolicismo popular, como en la mayoría de culturas, frente a los muertos se esperan más gestos de respeto y reconocimiento que frente a los vivos (Perrot, 1989: 157).

Gracias a este conjunto de rituales de interacción, el velorio promovía el fortalecimiento de los lazos comunitarios entre los dolientes, como los vínculos de parentesco, amistad y vecindad (González, 2002; Pochintesta, 2016). Después de la infaltable misa en una capilla católica, se depositaba el féretro en una tumba. Durante las noches siguientes, los dolientes celebraban el rito de las 9 noches. En estas, en palabras de un entrevistado, se reunían "para rezar el rosario y suplicar por el alma del difunto" (hombre de 67 años, comunicación personal, 09.11.2017), ya que, según la creencia popular, el alma permanece durante un período en el purgatorio, purificándose (a través del sufrimiento), antes de ingresar al cielo. Se cree que las oraciones y rosarios que ofrecen los dolientes ayudan al alma en pena a superar de manera exitosa este tránsito (Villa-Posse, 1993). Las 9 noches también ayudan a los dolientes en el proceso de elaboración del duelo, ya que durante los días que siguen al entierro, los deudos, especialmente los más afectados por la pérdida, no se encuentran solos, sino que gozan de la compañía de parientes, vecinos y amigos, que les brindan apoyo emocional.

Actualmente, en Colombia son escasos los ritos fúnebres que se celebran en los términos que acabamos de describir. ¿Cómo se explica este cambio? En buena medida, está relacionado con tres procesos fundamentales: 1) la creciente regulación del Estado sobre el trato que debe darse a los restos fúnebres; 2 ) el ascenso y consolidación de las empresas funerarias; y3) la globalización de las comunicaciones que les han permitido a los católicos acceder a información que, además de cuestionar la tradición, los ha llevado a ampliar el repertorio de las posibles maneras de despedirse de sus seres amados. En términos sociológicos, les ha permitido cuestionar la tradición y celebrar los ritos fúnebres de manera más reflexiva. A continuación, se describe con más detalle cada uno de estos procesos. 


\section{Regulación del rito fúnebre por parte del Estado}

En este apartado queremos mostrar cómo el Estado colombiano interviene cada vez más en el trato que debe darse a los restos fúnebres y en la manera como deben celebrarse los ritos fúnebres, asuntos que eran antes del dominio exclusivo de la Iglesia católica. A través de un proceso de larga duración, el Estado ha impuesto a los ciudadanos un conjunto de regulaciones que desplazan a un segundo plano los aspectos religiosos de los ritos fúnebres y modifican la forma en que los ciudadanos se relacionan con sus muertos y con el más allá. Al mismo tiempo, estas regulaciones refuerzan valores que son considerados propios de las sociedades modernas, como el interés general, el bien común y la salud pública.

Ya desde el siglo XIX, el Estado colombiano introdujo normas para regular los ritos fúnebres, argumentando razones de salud pública. Por ejemplo, determinó que los cuerpos debían ser enterrados en cementerios y no en iglesias o conventos (Ortega-Ricaurte, 1931). Como veremos, este proceso de regulación legal se aceleró en las últimas décadas del siglo XX. Exponemos, como ejemplo, algunas normas expedidas en este período:

1979: se estableció el Código Sanitario Nacional.

1982: se inició la reglamentación de necropsias y la certificación de defunciones. 1983: se reguló parcialmente la cremación.

1991: se definieron los trámites para la obtención de la licencia sanitaria de funcionamiento para las funerarias o agencias mortuorias (Secretaría Distrital de Salud de Bogotá, s.f.).

2004: se establecieron legalmente las condiciones higiénico-sanitarias de los establecimientos funerarios, así como las precauciones que deben tener todos aquellos que entran en contacto con los restos fúnebres para evitar los riesgos que estos pueden tener para la salud (Circular 28 de 2004 de la Secretaría Distrital de Salud).

2005: la Secretaría de Salud de Bogotá prohibióla celebración de velorios en inmuebles que no estén destinados para este propósito. Desde entonces, el velorio en casas de habitación o salones comunales es considerado ilegal (Prohíben velar, 2005).

Este conjunto de normas tuvo como una de sus consecuencias que los velorios dejaran de celebrarse en las casas de habitación y se trasladaran definitivamente a salas funerarias, lo cual repercutió profundamente en la forma y significado del rito fúnebre, tema que abordaremos más adelante. 
Como ejemplo de las transformaciones que ha ocasionado la regularización de las prácticas fúnebres, podemos citar el cambio en el rito de las 9 noches. Si bien este se celebra aún, parece tener cada vez menos importancia y menor poder de convocatoria. Solo lo guardan de manera estricta los dolientes más comprometidos con la fe católica, cuyo porcentaje está en descenso (Beltrán, 2012; Beltrán; Larotta, 2020; Pew Research Center, 2014), y, especialmente, aquellos que mantienen un fuerte vínculo afectivo con el difunto. Las razones por la cuales este rito viene en declive son diversas. Sin embargo, destacamos aquí las relacionadas con el proceso de regulación del duelo por parte del Estado. Por ejemplo, la Ley 1280 de 2009 (Código Sustantivo de Trabajo) estipula que, en caso de duelo, un empleador solo está obligado a liberar de sus obligaciones a su empleado por un máximo de 5 días. Así, desde el punto de vista legal, el empleado solo tiene 5 días (y no 9 como lo establece la tradición católica) para elaborar el duelo.

En los casos mencionados, la autoridad del Estado entra en conflicto con la de la Iglesia católica, y configura el proceso que Tschannen (1992) denomina mundanización: dimensión de la secularización que se expresa en la tendencia de las instituciones modernas de privilegiar los intereses mundanos (los de esta vida y este mundo, por ejemplo, los económicos y laborales) cuando estos entran en conflicto con los intereses del más allá (como la salvación del alma o la vida eterna). En el caso que nos ocupa, el Estado colombiano prioriza los asuntos mundanos como el bienestar general y la salud pública (prevenir epidemias o enfermedades que puedan desencadenarse a partir de cuerpos en descomposición), y valores mundanos, como la productividad económica, la eficiencia y el compromiso laboral. Todo esto en menoscabo de los valores religiosos y las tradiciones católicas. En este sentido, tal y como lo propone Hervieu-Léger (2005), el rito se desacraliza, en la medida en que en su ejecución se debilitan los significados que dotan de sentido al más allá y se atenúa su poder para ofrecer respuestas a las cuestiones últimas de la existencia.

Las regulaciones legales dieron un fuerte impulso a las empresas funerarias, que se consolidaron en torno a la monopolización de los procesos de inhumación, cremación y exhumación de los restos fúnebres.

\section{Consolidación y ascenso de las empresas funerarias}

Hasta mediados del siglo XX, las empresas funerarias se dedicaban casi exclusivamente a la comercialización de ataúdes. Esto empezó a cambiar en la segunda mitad de siglo, cuando la Funeraria Gaviria (Neira, 2017) inauguró las primeras salas de velación en el país. En la actualidad, decenas de empresas funerarias ofrecen sus servicios a los bogotanos, en tres sectores principales: 1) servicios de atención fune- 
raria, dentro de los que se destacan: la ayuda a los dolientes en trámites legales, la preparación del cuerpo (tanatopraxia), los servicios relacionados con el velorio, los servicios religiosos y el transporte de los restos fúnebres; 2) servicios de destino final (inhumación, cremación y oferta de tumbas, bóvedas o urnas) y de exhumación; y 3) infraestructura, es decir, la construcción y mantenimiento de cementerios e inmuebles que prestan servicios funerarios (Unidad Administrativa Especial Servicios Públicos, 2012). En Colombia, el negocio funerario se encuentra en plena expansión:

de acuerdo a la Federación Nacional de Comerciantes de Parques, Cementerios y Servicios Funerarios (FENALCO), en la nación (...) hay 9 parques cementerios, 871 cementerios, poco más de 1170 funerarias, (...) las circunstancias sociales y políticas por las que ha atravesado este país en las últimas décadas, ha favorecido el crecimiento del sector, a tal punto que se ha industrializado y masificado, a nivel de prestación de servicios funerarios para toda clase de personas. (Alcazar, 2018: s.p.)

Como toda empresa comercial, desde sus inicios, las funerarias han ofrecido una gama de servicios que le permiten a los dolientes encontrar símbolos de distinción social (Bourdieu, 1999). Inicialmente, estos símbolos se relacionaban con la calidad y lujo de los féretros. A medida que las funerarias han ampliado la gama de servicios que ofrecen (salas de velación, carrosas fúnebres, destinos de los restos fúnebres, entre otros), se ha dado también un proceso de estratificación simbólica de su oferta. Así, los católicos populares suelen pensar que un entierro más costoso les otorga beneficios de distinción social.

El traslado del velorio de casas de habitación a salas de velación ha ampliado la dimensión comercial del rito fúnebre. Ahora, por medio de este tipo de ritos no solo se ponen en escena los sentimientos que buscan fortalecer los vínculos comunitarios, sino que entran en juego las tensiones propias de las transacciones económicas, que tienen lugar entre los dolientes (que compran una serie de servicios) y las empresas funerarias (que los venden).

De esta manera, el rito fúnebre deja de ser exclusivamente comunitario, para adquirir una dimensión impersonal y comercial. En palabras de León (1997: 168), las funerarias constituyen "la expresión visible de un proceso consciente de comercialización de la muerte”. En este proceso, algunos de los dolientes adquieren el rol de clientes que compran servicios a desconocidos. Paradójicamente, este tránsito (de doliente a cliente) les ha permitido a los dolientes ganar autonomía con respecto a la Iglesia católica y sus sacerdotes, en lo referido a la forma y significado del rito, puesto que en la medida que las empresas funerarias evolucionan para responder de manera eficiente a las expectativas y deseos de sus clientes, relegan a un segundo plano las orientaciones o recomendaciones de las instituciones religiosas acerca de 
la correcta ejecución de los ritos fúnebres. En otras palabras, el afán de las empresas funerarias por satisfacer el deseo de sus clientes conlleva una dinámica que transforma el rito fúnebre, e implica un nuevo paso en el proceso de su autonomización frente al control de la Iglesia católica.

Por otro lado, así como las funerarias se sienten con autoridad de regular los ritos que se celebran en sus instalaciones, el desplazamiento del velorio a las salas funerarias ha implicado un proceso de burocratización del ritual, que ahora queda, en mayor medida, en las manos de funcionarios que no pertenecen a los círculos comunitarios del difunto ni de los dolientes.

Por último, puesto que los dolientes suelen desconocer la legislación vigente en lo referente al trato que debe dársele a los restos fúnebres, tienden a confiar en las orientaciones que, sobre este asunto, les ofrecen las empresas funerarias, y a dejar en manos de estas los trámites legales pertinentes. Esto ha permitido que estas empresas asuman el papel de asesoras en asuntos legales y religiosos (Bedoya, 2015). Este tipo se asesoría se ofrece incluso sin haber sido solicitada por los dolientes, y en ella los asesores no suelen explicar las diferencias entre las regulaciones que provienen del Estado y aquellas que las empresas funerarias introducen y que se originan en sus propios intereses económicos.

Un ejemplo de este tipo de regulaciones es el límite que las empresas funerarias imponen a los dolientes en lo referido al tiempo que debe durar el velorio. Como ya señalamos, cuando los restos fúnebres eran velados en las casas de habitación, el rito se extendía a lo largo de toda la noche. Ahora, las empresas funerarias les exigen a los dolientes retirarse de las salas de velación a más tardar a las 10 p. m., y reanudar el rito al día siguiente, sin conmoverse por las implicaciones emocionales y simbólicas que para los dolientes pueda acarrear el hecho de abandonar los restos de sus seres amados (Villa-Posse, 2002).

Otro aspecto donde se observa con claridad que la intervención de las empresas fúnebres atenta contra el carácter comunitario del ritual e impone unas prácticas impersonales, radica en el hecho de que los dolientes delegan en las empresas funerarias todas las tareas relacionadas con la tanatopraxia, la sepultura o la cremación. Como ya se mencionó, en la tradición católica popular, la preparación del cuerpo estaba a cargo de los dolientes, especialmente de los más vinculados emocionalmente con el difunto y hacía parte del conjunto de ritos por medio de los cuales estos se despedían de sus seres amados. Ahora, gracias a la legislación vigente y por la intervención de las empresas funerarias, la preparación del cuerpo queda en manos de personal especializado que en este proceso privilegia las pautas profesionales relacionadas con la higiene y la salud pública. Juan Pablo del Alcazar (2018: s.p.), consultor de marketing para la industria funeraria, hace las siguientes precisiones al respecto: 
En las funerarias, se busca que el proceso de tanato-estética sea de primer nivel, para que el difunto tenga un aspecto totalmente natural, prácticamente idéntico al que tuvo en vida, sin que esto implique algún trauma o desagrado para las personas que asistan al funeral, tomando en cuenta todas las necesidades que tiene el cuerpo: extracción de sondas, aseo, taponamiento para evitar pérdida de fluidos, hidratación, entre otros. No se debe olvidar el vestuario, que puede ser un uniforme, alguna indumentaria religiosa, ropa de calle o cualquier otra cosa. Y el peinado se hace tras ver una foto de la forma en que se peinaba la persona.

Así, en el proceso de preparación del cuerpo para la sepultura prácticamente desaparecen las dimensiones simbólicas, religiosas y afectivas antaño relacionadas con este ritual (Thomas, 1989). La preparación del cuerpo queda así reducida a "un servicio entre otros tantos que se ofrecen en la sociedad de consumo" (Pochintesta, 2016:57).

La relación entre los funcionarios de las empresas fúnebres (que llamaremos agentes funerarios) y los dolientes-clientes se puede analizar por medio del modelo de pautas variables que propuso Parsons (1988). En el aspecto emocional, el agente funerario se rige por la pauta de la neutralidad afectiva, en otras palabras, se resiste a identificarse afectivamente con los dolientes. Esta actitud contrasta con la dimensión afectiva propia del rito fúnebre que ayuda a los dolientes a fortalecer los lazos comunitarios. Asimismo, el agente funerario se guía por lo que Parsons (1988) denomina el principio universalista de expectativa de rol, en otras palabras, intenta, en la medida de lo posible, relacionarse con sus clientes a partir de pautas universales: trata a todos sus clientes de la misma manera, sin tener en cuenta sus particularidades personales y el carácter único de su drama. En cuanto a los intereses económicos, el agente funerario privilegia los intereses de la empresa para la que trabaja, por lo cual se esmera en vender la mayor cantidad de servicios a los dolientes, incluso aquellos que él mismo considera innecesarios. Así, aunque en apariencia se muestra sinceramente interesado por el doliente, su principal motivación es lograr la mayor rentabilidad en el contrato comercial que está perfeccionando. En todos estos aspectos se deteriora el carácter personal y comunitario del rito, y se impone la lógica impersonal y burocrática que conviene a las empresas funerarias.

Si bien es cierto que la burocratización y despersonalización del rito fúnebre implican para los dolientes enfrentar experiencias emocionalmente desagradables, las empresas funerarias se esmeran en humanizar el rito fúnebre, por lo cual también ofrecen, entre sus servicios, acompañamiento psicológico, con la intención de ayudar al doliente en el manejo de su dolor. De esta manera, las empresas funerarias, responsables del proceso de burocratización y despersonalización del rito, paradójicamente se esmeran por presentarse ante sus clientes preocupadas por ofrecer vías profesionales para humanizar los ritos fúnebres (Bedoya, 2015). 
En la medida en que las empresas funerarias compiten entre sí para atraer y fidelizar la mayor cantidad de clientes, actúan bajo una lógica de campo, entendiendo este en términos de la teoría de Bourdieu (1990). Cuando hablamos del campo de las empresas fúnebres, subrayamos las lógicas de rivalidad y competencia que dinamizan el mercado de los servicios fúnebres. Esta competencia incentiva la creación de nuevos servicios (o innovación) que, a su vez, tienen el potencial de ofrecer nuevos beneficios simbólicos a los dolientes o de brindarles la sensación de estar celebrando el rito de la mejor manera posible (Funerarias colombianas, 2015).

La competencia de las empresas funerarias incentiva la autonomía de los ritos fúnebres con respecto a su vínculo con la tradición católica. Esto no significa que las nuevas alternativas rituales que ofrecen las funerarias sean necesariamente incompatibles con las creencias católicas, pero sí que se sustentan en valores que no necesariamente son propios de esta religión. Por ejemplo, teniendo en cuenta la creciente preocupación por el medio ambiente como uno de los valores en ascenso de nuestro tiempo, algunas empresas funerarias ofrecen entierros ecológicos, con productos y tratamientos del cuerpo que permiten "disminuir al máximo la huella ecológica" (Funerarias colombianas, 2015), estos incluyen ataúdes y urnas biodegradables. Otras ofrecen paquetes turísticos para complementar el rito del velorio o para facilitarle a los dolientes el desplazamiento a un determinado lugar donde se esparcirán las cenizas de los restos fúnebres que han sido cremados (Cenizas al mar, 2018). Uno de los aspectos en que los intereses económicos de las empresas funerarias riñen con frecuencia con las orientaciones de la Iglesia católica se relaciona con la promoción que estas hacen de la cremación de los cuerpos, rito que está desplazando a la inhumación o sepultura (Funerarias colombianas, 2015).

\section{De la sepultura a la cremación}

En la actualidad, algunas de las empresas funerarias en Colombia privilegian, en su oferta de servicios, la cremación sobre la inhumación. Entre los argumentos con los que sustentan esta recomendación incluyen: 1) la cremación es un rito de menor costo económico que el entierro; 2) "los dolientes pueden decidir el destino final de las cenizas" (Funerarias colombianas, 2015: s.p.); 3) las tumbas pueden ser profanadas, y el material orgánico puede ser robado y usado ilegalmente, lo cual es imposible con restos fúnebres que han sido incinerados; y 4) la cremación implica un tratamiento de los restos fúnebres "más respetuoso con el medio ambiente" (Funerarias colombianas, 2015: s.p.). A estas razones, añaden que la cremación es un rito aceptado por la Iglesia católica. En estos argumentos se puede observar, 
otra vez, el ascenso de nuevos valores. Por ejemplo, además de las preocupaciones económicas, emergen otras ecológicas e incluso preocupaciones relacionadas con el valor del material genético de los difuntos.

Nos interesa especialmente mostrar que algunas de las recomendaciones de las funerarias sobre el trato que puede dársele a las cenizas entran en conflicto con las orientaciones que ofrece la Iglesia católica sobre el adecuado trato que debe darse a los restos fúnebres y cuestionan algunos de los valores católicos tradicionales. Para la tradición católica, el rito de sepultar los cuerpos se remonta al cristianismo primitivo: los primeros cristianos quisieron seguir el ejemplo de su salvador, quien al morir fue sepultado. Además, la sepultura se relaciona con la esperanza cristiana de la futura resurrección del cuerpo para el juicio final (Pochintesta, 2016). La costumbre de sepultar a los muertos se generalizó con el ascenso del cristianismo como religión oficial del Imperio Romano, cuando la Iglesia católica ya condenaba la cremación, con el argumento de que esta privaba al alma de una posible resurrección.

El retorno de la cremación a las sociedades cristianas se relaciona con la invención de la cámara de cremación en 1873. Inicialmente, el rito de incinerar los cuerpos encontró acogida entre sectores que no se identificaban con el catolicismo (como librepensadores y protestantes). Frente a este fenómeno, en enero de 1964, en el Acta Apostolicae Sedis, la Iglesia católica se pronunció para recomendarle a sus fieles mantener la costumbre de sepultar el cadáver de los difuntos. Precisó, sin embargo, que la cremación no es "contraria a ninguna verdad natural o sobrenatural", siempre que no obedezca a la "negación de los dogmas cristianos", especialmente a la negación de la creencia en la resurrección.

En Colombia, el primer horno crematorio se instaló en 1980 en la ciudad de Medellín. Para 1998, se habían creado más de diez hornos en todo el país y se incineraba cerca del $20 \%$ de los fallecidos. Rápidamente, la cremación encontró acogida entre los católicos por el alto costo de los entierros y el carácter traumático de asistir a "la exhumación de los cuerpos luego de varios años de sepultados" (Cremaciones, 1998: s.p.), sentimiento compartido por los entrevistados. Una de ellas comentó: "es mejor la cremación porque hay un solo dolor, porque (...) es muy [triste] ir a ver sacar los restos, [y] tener que volver a pagar para cremarlos" (mujer de 74 años, comunicación personal, 05.10.2017).

En 2016, la Congregación para la Doctrina de la Fe reiteró que la inhumación es el rito fúnebre ideal para quienes profesan la fe católica:

Siguiendo la antiquísima tradición cristiana, la Iglesia recomienda insistentemente que los cuerpos de los difuntos sean sepultados en los cementerios u otros lugares sagrados. (...) Enterrando los cuerpos de los fieles difuntos, la Iglesia confirma su fe en la resurrección de la carne, y pone de relieve la alta dignidad del cuerpo humano (...). 
Si por razones legítimas [higiénicas, económicas o sociales] se opta por la cremación del cadáver, las cenizas del difunto, por regla general, deben mantenerse en un lugar sagrado, es decir, en el cementerio o, si es el caso, en una iglesia o en un área especialmente dedicada a tal fin por la autoridad eclesiástica competente (...).

Por las razones mencionadas anteriormente, no está permitida la conservación de las cenizas en el hogar. (...) Para evitar cualquier malentendido panteísta, naturalista o nihilista, no sea permitida la dispersión de las cenizas en el aire, en la tierra o en el agua o en cualquier otra forma, o la conversión de las cenizas en recuerdos conmemorativos, en piezas de joyería o en otros artículos (...). En el caso de que el difunto hubiera dispuesto la cremación y la dispersión de sus cenizas en la naturaleza por razones contrarias a la fe cristiana, se le han de negar las exequias, de acuerdo con la norma del derecho. (Congregación para la Doctrina de la Fe, 2016: s.p.)

Es en lo relacionado con el destino final de las cenizas donde se encuentra la mayor tensión entre las orientaciones de la Iglesia y las ofertas de las empresas funerarias. Los servicios funerarios ofrecen múltiples alternativas en este sentido: las cenizas pueden ser depositadas en un cementerio, en un nicho o columbario; pueden reposar en la casa del fallecido, o en joyas como collares o anillos; se puede encargar una pintura al óleo elaborada con "una mezcla de pintura y cenizas" (Qué hacer, 2018a: s.p.). Además, se puede también plantar un árbol junto a ellas, crear un diamante, "mezclarlas con barro para crear una escultura", "esparcir las cenizas en el mar" o en un río, depositarlas "en el columbario de [un] estadio de fútbol", "esparcir las cenizas en un viaje en globo" o, simplemente, "conservarlas en una urna" en el lugar que prefieran el difunto o los dolientes (Qué hacer, 2018b: s.p.).

Según la información suministrada por los entrevistados, los dolientes católicos que optan por la cremación de sus seres amados lo hacen especialmente por razones económicas, pues, por esta vía, toda la cadena ritual resulta más barata (Orozco-Girón, 2019). Una tendencia similar se puede observar en otros lugares de América Latina (Pochintesta, 2016). Sin embargo, también manifiestan otras motivaciones, como razones ecológicas o el acceso a símbolos de distinción; por ejemplo, los atrae la oportunidad de poseer joyas, monumentos o cuadros elaborados con las cenizas del difunto.

Cremación, nosotros [optamos por la] cremación. Sea que yo me vaya primero o ella [mi esposa] se vaya primero, preferimos la cremación (...). El problema es que en [las funerarias] no, sino buscar en una iglesia, porque en [las funerarias] vale ya casi dos millones [de pesos colombianos] un osario, y eso, hay que pagar para todo. (Hombre de 77 años, comunicación personal, 24.10.2017) 
Algunos optan por la cremación para dar cumplimiento al último deseo de su ser amado, ya que crece el número de católicos que manifiestan expresamente su deseo de ser incinerados e, incluso, eligen para sus cenizas un destino diferente a una iglesia o un camposanto (Orozco-Girón 2019: 65): "hay personas que desean que sus cenizas sean esparcidas en lugares especiales o con mucho valor o significado para ellos, como la casa de su niñez" (Qué hacer, 2018b: s.p.). Como ejemplo, es útil el comentario en extenso de una de las entrevistadas:

Mi madre que es muy católica nos dice que cuando muera quiere que la crememos y esparzamos sus cenizas en un río. Eso porque ella siente que eso podría darle más tranquilidad a su alma, al estar conectada de cierta manera con la naturaleza o ser parte de ella, y porque cree que para nosotros será mucho más amable y tranquilizante saber que ella está en el aire y no en un lugar fijo [como una tumba o un columbario], al cual probablemente nos sentiríamos obligados a visitarla. (Mujer de 30 años, comunicación personal, 12.10.2019)

En este sentido, con conciencia o sin ella, los católicos se ubican en expresa contravía de las orientaciones de su Iglesia. La gran mayoría de los católicos entrevistados manifestó el deseo de ser cremado, y ninguno reveló un conflicto subjetivo al respecto. Los entrevistados que no querían ser cremados tampoco expresaron cuestionamientos o reproches que sancionaran a quienes optaban por la cremación para sí mismos o para sus parientes.

Que mis cinco nietos esparzan mis cenizas con alegría y diciendo: "adiós, abuela". Si no encuentran el río cristalino, entonces al viento. Y que no se crean lo que dice ahora el (...) papa Francisco, que hay que llevarlas al cementerio o a las iglesias, porque o si no, se les acaba el negocito. (Mujer de 71 años, comunicación personal, 01.08.2017)

Tal y como lo expresa el documento de la Congregación para la Doctrina de la $\mathrm{Fe}$ (2016), el cambio en el rito (de la sepultura a la cremación) puede estar acompañado del afianzamiento de nuevos significados sobre la muerte y el destino del difunto. Así, al parecer, la cremación les facilita a los católicos simpatizar con ideas como el panteísmo o la reencarnación, que son contrarias al dogma católico. Por otro lado, todo parece indicar que los católicos que ya simpatizan con ideas sobre la muerte y el más allá no aceptadas por su Iglesia optan con mayor frecuencia por la cremación.

La consolidación de la cremación amenaza el rito católico de la exhumación, el cual se celebra 4 años después del fallecimiento y consiste en desenterrar los restos fúnebres y trasladarnos a una urna, pero que se observa cada vez con menor 
frecuencia. Ahora bien, al parecer, la consolidación de la cremación como rito legítimo es propia de los contextos urbanos. Según la información suministrada por los entrevistados, en las zonas rurales se sigue guardando con mayor celo la tradición de sepultar los cuerpos.

\section{El rito fúnebre en el mundo globalizado}

Por último, nos preguntamos cuál ha sido la influencia de los medios de comunicación masiva en el proceso de secularización de los ritos fúnebres. Si bien ya hacia mediados del siglo XX la sociedad colombiana se vio expuesta a información que cuestionaba los ritos y los valores católicos, y que era difundida especialmente por el cine, televisión y revistas de circulación global como Cosmopolitan y Playboy (Bastidas; Beltrán, 2019; Méndez, 2004), ha sido la masificación de la internet y, particularmente, la de las redes sociales, el fenómeno que más ha contribuido a la secularización de los ritos fúnebres.

En la cultura católica popular, era frecuente visitar la tumba de los seres amados para conversar con ellos o, incluso, para solicitarles favores. Así, el cementerio constituía el lugar por excelencia para el encuentro entre vivos y muertos. Además, una manera de honrar a los seres amados fallecidos era cuidar, limpiar o decorar sus tumbas, y llevarles ofrendas florales, costumbre que también se ha erosionado, en parte, por la creciente práctica de incinerar los cuerpos (Villa-Posse, 1993). En todo caso, sin que estas costumbres hayan desaparecido por completo, en la sociedad bogotana, las tumbas poco a poco han ido perdiendo importancia como referente espacial para recrear la memoria y honrar a los difuntos. Al parecer, la tumba, como lugar de referencia para el encuentro entre vivos y muertos, viene siendo desplazada por nuevos espacios y símbolos.

Así, como se señaló anteriormente, cada vez con más frecuencia, los católicos desean mantener lo más cerca posible los restos de sus seres amados, ya sea en urnas, joyas o, incluso, en obras de arte que contienen o han sido fabricadas con las cenizas producto de la cremación. Estos objetos constituyen ahora referentes para la memoria y símbolos de veneración que facilitan la comunicación de los dolientes con sus difuntos.

Sin embargo, el avance de las nuevas tecnologías de la información, particularmente la masificación de internet, ha abierto nuevos espacios para la relación entre los dolientes y sus muertos. La primera evidencia de este proceso se cristalizó con la masificación de Facebook (creada en 2004), plataforma tecnológica que permite consolidar y mantener redes de amigos y conocidos que intercambian todo tipo de in- 
formación (textos, fotografías, videos, etc.). Cuando un usuario de Facebook fallece, ocurre con frecuencia que su perfil continúa activo, esto permite que los contactos del fallecido sigan recibiendo notificaciones (mensajes) acerca de fechas significativas para él, como, por ejemplo, la fecha en que se celebraba su cumpleaños. Además, los contactos pueden seguir enviando mensajes al perfil del difunto. Esto permite que los perfiles de Facebook se constituyan como medios de comunicación de los dolientes con el difunto y símbolos para rememorarlos. Por ejemplo, los dolientes pueden visitar el perfil de sus seres fallecidos y revivir el contenido que este solía compartir, pero, además, una persona puede configurar su cuenta de Facebook para que esta siga funcionando como una cuenta conmemorativa después de su muerte, autorizando a "otra persona para que [al momento de su muerte] gestione el perfil" (García-Nieto, 2017). Este procedimiento permite que la cuenta se mantenga activa en memoria del difunto.

En las opciones de administración de las cuentas de sus usuarios, Facebook explica que "las cuentas conmemorativas son un lugar para que amigos y familiares se reúnan y compartan recuerdos de un ser querido que falleció”. Por medio de estas cuentas, por ejemplo, "los amigos [del difunto] pueden compartir recuerdos en la biografía conmemorativa", y consultar "el contenido que la persona [fallecida] haya compartido (por ejemplo, fotos, publicaciones, etc.)". Algo similar ha sido implementado por otras plataformas tecnológicas del tipo redes sociales.

Por lo tanto, la masificación de internet ha traído consigo nuevos medios y símbolos que están trasformando la interacción entre los dolientes y sus muertos (Gamba, 2007a; 2007b). Estas plataformas tecnológicas se constituyen también como espacios donde se consolidan ritos póstumos sin mediación o control proveniente de la Iglesia católica, el Estado o las empresas funerarias. Además, ninguna de las instituciones mencionadas está en la capacidad de regular este nuevo fenómeno. Por lo tanto, la emergencia del espacio virtual ha implicado un nuevo paso en el proceso de autonomización de los ritos fúnebres.

Por ejemplo, según la costumbre católica, al año de la muerte de un ser querido se celebraba una misa para rezar por su alma y se solía visitar su tumba. Ahora, muchos dolientes no siguen esta tradición, como lo confirmaron algunos de los entrevistados, sino que se limitan a compartir un mensaje conmemorativo entre sus contactos usando Facebook u otra red social.

A mí casi no me gusta exteriorizar mis cosas (...), porque los sentimientos son privados, pero si hub[o] ciertas cosas. Por ejemplo, a los tres meses [desde la muerte de mi amiga] recuerdo que (...) la hija de ella (...) fue al cementerio y le tomó foto a la lápida, y escribió en su perfil de Facebook: “mamá (...), te extraño (...), la vida ya no es la misma”. 
Y yo lo compartí, porque de todas maneras es muy duro. Y, por ejemplo, ayer fue la misa [de un año de fallecida] y yo no pude ir porque estuve en clase como hasta las 8. [Entonces] llegué [a casa] y puse [en Facebook] una foto muy bonita que le tomé, y la compartí hoy, y escribí que me parece mentira que no esté [viva]. (Hombre de 23 años, comunicación personal, 21.09.2017)

Las funerarias han visto el potencial económico de este fenómeno, por lo cual se han apresurado a ofrecer cementerios o tumbas virtuales, que operan de forma similar a las plataformas tecnológicas ya descritas. Por ejemplo, la funeraria Los Olivos, en su página web, promociona así su cementerio virtual:

Los Olivos Cementerio Virtual, diseñado para que la familia y los amigos puedan acceder y configurar un espacio dedicado a todas aquellas personas y seres queridos que han partido, haciendo posible publicar fotos, subir videos, seleccionar oraciones, recibir condolencias, enviar flores y encender velas virtuales. Esto permite a los familiares, amigos y allegados realizar una visita virtual en ese espacio reservado para ese ser especial que se fue y que por alguna razón no podemos visitar en el cementerio físicamente (...). Con este servicio Los Olivos ha querido prolongar más allá de la realidad, el verdadero sentido de la muerte. El "sentido humano" que profesamos nos permite generar acciones como estas, tendientes a mantener vivo el recuerdo de nuestros seres queridos y que nos hacen pensar que su partida no ha sido un adiós sino un hasta pronto.

Es pertinente aclarar que el uso de los espacios virtuales para la celebración de ritos sagrados es más frecuente entre la población joven, que está más familiarizada con la interacción a través de estos medios. Al parecer, este fenómeno corresponde a un cambio de mentalidad cuyas dimensiones y consecuencias deben ser investigadas con mayor profundidad (Gamba, 2007a; 2007b).

Los sacerdotes católicos son conscientes de este proceso, y algunos responden tratando de adaptarse a los nuevos tiempos. En esta vía, ofrecen nuevos servicios que en el intento de mantener la tradición la transforman. Por ejemplo, la Iglesia católica cuenta ya con su propia página en Facebook, del mismo modo que la tienen numerosas parroquias y párrocos. Por este medio, ofrecen a sus fieles todo tipo de servicios religiosos, incluidas transmisiones en vivo de ceremonias fúnebres. Así, aquellos dolientes que no puedan hacer presencia física participan del rito de manera virtual o remota. 


\section{Conclusiones}

En Colombia, la secularización del rito fúnebre se expresa en la creciente intervención de instituciones y actores diferentes a la Iglesia católica (especialmente el Estado y las empresas funerarias) en la regulación de los ritos fúnebres y el trato que debe darse a los restos fúnebres, intervención que, a su vez, ha modificado este conjunto de ritos y sus significados. Así, el trato que debe dársele a los muertos ha dejado de ser un asunto de interés exclusivo de esta Iglesia.

Nuevos valores que también escapan al control de la Iglesia católica vienen desplazando a los valores católicos tradicionales. Para los fieles, las preocupaciones por el bienestar de las almas o el descanso de sus muertos han cedido frente a valores relacionados con la salud y la higiene (por ejemplo, no contaminarse con restos orgánicos) o frente a valores estéticos (como los que se expresan en la posibilidad de transformar las cenizas de los difuntos en artículos de ornato, de atavío u obras de arte). En este proceso, los intereses de esta vida pasan a primer plano, al mismo tiempo que las preocupaciones relacionadas con el destino eterno o la salvación de las almas pierden importancia.

En la medida en que el rito ha quedado sujeto a las lógicas del mercado y a la regulación del Estado, la legitimidad de los representantes de la Iglesia católica, a saber, de los sacerdotes, se ha devaluado. Esto no significa que el sacerdote haya perdido por completo la autoridad para orientar a los fieles en lo concerniente a la adecuada ejecución de los ritos fúnebres, sino, más bien, que su voz es ya solo una entre otras muchas que se sienten autorizadas para guiar a los dolientes al respecto. Además, mientras la legitimidad de la autoridad del sacerdote se devalúa, se legitima la idea según la cual los católicos tienen derecho a decidir cómo deben ser tratados sus restos fúnebres, y los dolientes se sienten con el derecho a decidir cuál es la manera más adecuada de despedir a sus seres amados, cuáles son los símbolos más pertinentes para recordarlos y cómo deben ser tratados sus restos después de la muerte. Así, sin renunciar a su fe, los católicos encuentran legítimo escoger, en el marco de una creciente oferta, los ritos y símbolos que se acomodan mejor a sus gustos y expectativas.

Esto no significa que las formas tradicionales de celebrar el rito desaparezcan, sino que parecen destinadas a convertirse en una opción más, entre muchas posibles. En este sentido, la secularización de los ritos fúnebres también se relaciona con el ascenso de todos los valores vinculados a la autonomía del sujeto y al creciente empoderamiento del actor individual que impone nuevas demandas a la Iglesia católica y, en general, a las instituciones religiosas. Así, siguiendo a Hervieu-Léger (1999; 2005), el rito fúnebre tiende a la desacralización, en la medida en que su carácter 
sagrado queda subordinado a nuevos valores entre los que se destacan la libertad y la autonomía del actor individual.

Por último, reiteramos que los cambios aquí descritos se están dando de manera más acelerada en los contextos urbanos. En contraste, en los sectores rurales, los católicos se mantienen más apegados a la tradición católica popular y la autoridad del sacerdote sufre menos cuestionamientos.

\section{Referencias}

Alcazar, Juan Pablo del (26 de noviembre de 2018). Cambios y tendencias del sector funerario en América Latina. All Funer. Recuperado de https://allfuner.com/es/tendencias-delsector-funerario-en-america-latina/

Bastian, Jean-Pierre (1997). La mutación religiosa en América Latina: para una sociología del cambio social en la modernidad periférica. México: FCE.

Bastidas, Luis Bernardo; Beltrán, William Mauricio (2019). The Reaction of the Colombian Catholic Church to the Secularization of Sexual and Reproductive Life (1960-1980). Sexuality \& Culture, 23, 906-926. https://doi.org/10.1007/s12119-019-09596-5

Bedoya, David (2015). Caracterización del sector funerario y la tanatopraxia en Colombia. Bogotá: SENA.

Beltrán, William Mauricio (2012). Descripción cuantitativa de la pluralización religiosa en Colombia. Universitas humanistica, 73(73), 201-237. Recuperado de https://revistas. javeriana.edu.co/index.php/univhumanistica/article/view/3636

Beltrán, William Mauricio (2013). Del monopolio católico a la explosión pentecostal. Bogotá: Universidad Nacional de Colombia.

Beltrán, William Mauricio; Larotta, Sonia (2020). Diversidad religiosa, valores y participación política en Colombia. Resultados de la encuesta nacional sobre diversidad religiosa 2019. Bogotá: Act IS/WV/CIJP/UNAL.

Berger, Peter (2006). El dosel sagrado: elementos para una sociología de la religión. Barcelona: Kairos.

Bourdieu, Pierre (1990). Sociología y cultura. México: Grijalbo.

Bourdieu, Pierre (1999). La distinción. Criterio y bases sociales del gusto. Madrid: Taurus.

Calvo, Oscar Iván (1998). El cementerio central, la vida urbana y la muerte. Bogotá: Tercer Mundo/Observatorio de Cultura Urbana. 
Casanova, José (2012). Genealogías de la secularización. Barcelona: Anthropos.

Cenizas al mar (2018). Capillas de la Fe. Recuperado de https://capillasdelafe.com/producto/ cenizas-al-mar

Collins, Randall (2009). Cadenas de rituales de interacción. Barcelona: Anthropos.

Congregación para la Doctrina de la Fe (2016). Instrucción Ad resurgendum cum Christo acerca de la sepultura de los difuntosy la conservación de las cenizas en caso de cremación. Recuperado de http://www.vatican.va/roman_curia/congregations/cfaith/documents/rc_con_cfaith_ doc_20160815_ad-resurgendum-cum-christo_sp.html

Cremaciones le abren hueco a los cementerios (29 de abril de 1998). El Tiempo. Recuperado de http://www.eltiempo.com/archivo/documento/MAM-779257

Davie, Grace (2011). Sociología de la religión. Madrid: Akal.

Dobbelaere, Karel (1981). Trend Report Secularization: A Multi-dimensional Concept. Current Sociology, 29(2), 3-153. https://doi.org/10.1177/001139218102900203

Durkheim, Émile (1982). Las formas elementales de la vida religiosa: el sistema totémico en Australia. Madrid: Akal.

Escovar, Alberto (2002). El cementerio central de Bogotá y los primeros cementerios católicos. Credencial Historia, 155, 13-15. Recuperado de http://www.revistacredencial.com/ credencial/historia/temas/el-cementerio-central-de-bogota-y-los-primeros-cementerioscatolicos

Eliade, Mircea (1998). Lo sagrado y lo profano. Barcelona: Paidós.

Funerarias colombianas también se montan en la ola de la innovación (2015). Semana. Recuperado de https://www.semana.com/empresas/articulo/sector-funerario-colombiareinventa-innovacion/212817/

Gamba, Fiorenza (2007a). La mort en Réseau : une re-sacralisation post-moderne. International Review of Sociology, 17(1), 135-148. http://dx.doi.org/10.1080/03906700601129707

Gamba, Fiorenza (2007b). Rituels postmodernes d'immortalité : les cimetières virtuels comme technologie de la mémoire vivante. Sociétés, 3, 109-123. http://dx.doi.org/10.3917/ soc.097.0109

García-Canclini, Néstor (1989). Culturas híbridas. Estrategias para entrary salir de la modernidad. México: Grijalbo.

García-Nieto, Jose (2017). ¿Qué pasa con la cuenta de Facebook cuando el dueño se muere? Andro 4 All. Recuperado de https://andro4all.com/2017/04/que-pasa-cuenta-facebookcuando-dueno-muere 
Giddens, Anthony (1993). Las nuevas reglas del método sociológico. Crítica positiva de las sociologías interpretativas. Buenos Aires: Amorrortu.

González, José Luis (2002). Fuerza y sentido: el catolicismo popular al comienzo del siglo XXI. México: Dabar.

Hervieu-Léger, Danièle (1999). Le pèlerin et le converti. La religion en mouvement. París: Flammarion.

Hervieu-Léger, Danièle (2005). La religión, hilo de memoria. Barcelona: Herder.

León, Marco Antonio (1997). Sepultura sagrada, tumba profana. Los espacios de la muerte en Santiago de Chile, 1883 - 1932. Santiago de Chile: LOM Ediciones.

Luckmann, Thomas (1967). The Invisible Religion: The Problem of Religion in Modern Society. Nueva York: Macmillan.

Mallimaci, Fortunato (2017). Modernidades religiosas latinoamericanas. Un renovado debate epistemológico y conceptual. Caravelle, 108,15-33. https://doi.org/10.4000/caravelle.2218

Martin, David (2002). Pentecostalism: The World Their Parish. Oxford: Blackwell Publishing.

Martin, David (2005). On Secularization. Towards a Revised General Theory. Farnham: Ashgate.

Marzal, Manuel (2002). Tierra encantada. Madrid: Trotta.

Méndez, Sergio (2004). Cine e iglesia en los años sesenta. En Iglesia Católica, artey secularización en Colombia en las décadas de 1960 y 1970 (pp. 8-21), coordinado por Laura Barragán. Bogotá: Universidad de los Andes.

Molina, David (2013). Tumbas de indignos: cementerios no católicos en Colombia 1825-1991 (Tesis de doctorado). Universidad Nacional de Colombia, Facultad de Ciencias Humanas y Económicas, Doctorado en Historia, Bogotá.

Morello, Gustavo (2017). Modernidad y religiosidad en América Latina. Razóny Fe, 276(1429), 327-338. Recuperado de https://revistas.comillas.edu/index.php/razonyfe/article/ view/9265

Neira, Armando (21 de octubre de 2017). De taller de ebanistería a funeraria de presidentes. El Tiempo. Recuperado de https://www.eltiempo.com/economia/empresas/130-anos-dehistoria-de-la-funeraria-gaviria-143432

Orozco-Girón, Lyanne Zuleinny (2019). Economía culturaly rituales funerarios. Transformaciones en el contexto de Popayán (Tesis de maestría). Universidad del Cauca, Facultad de Ciencias Contables, Económicas y Administrativas, Maestría en Estudios Interdisciplinarios del Desarrollo, Popayán.

Ortega-Ricaurte, Enrique (1931). Cementerios de Bogotá. Bogotá: Cromos. 
Parker, Cristián (1996). Otra lógica en América Latina. Religión popular y modernización capitalista. Santiago de Chile: FCE.

Parsons, Talcott (1988). El sistema social. Madrid: Alianza.

Perrot, Michelle (1989). Figuras y funciones. En Historia de la vida privada. De la Revolución Francesa a la Primera Guerra Mundial (pp. 50-72), dirigido por Philippe Ariés; Georges Duby. Madrid: Taurus.

Pew Research Center (2014). Religión en América Latina: cambio generalizado en una región históricamente católica. Recuperado de https://www.pewresearch.org/wp-content/uploads/ sites/7/2014/11/PEW-RESEARCH-CENTER-Religion-in-Latin-America-OverviewSPANISH-TRANSLATION-for-publication-11-13.pdf

Pochintesta, Paula Analia (2016). La ritualidad en transición. Un estudio sobre las preferencias del destino corporal. Athenea Digital,16(2), 33-66. Recuperado de http://www.redalyc.org/ articulo.oa?id=53746594002

Prohíben velar muertos en casas (18 de mayo de 2005). El Tiempo. Recuperado de http://www. eltiempo.com/archivo/documento/MAM-1623179

¿Qué hacer con las cenizas de un ser querido? (2018a). Mapfre. Recuperado de https://www. mapfre.es/seguros/particulares/vida-accidentes/seguros-de-decesos/articulos/cenizasser-querido.jsp

¿Qué hacer con las cenizas de un ser querido? (2018b). Terranea. Recuperado de http://www. terranea.es/blog/que-hacer-cenizas-de-un-ser-querido/

Roux, Rodolfo de (2017). La Iglesia católica en América Latina a la hora del papa Francisco. Caravelle, 108, 35-49. https://doi.org/10.4000/caravelle.2244

Secretaría Distrital de Salud de Bogotá (s.f.). Funerarias, cementerios y hornos crematorios. Recuperado de http://www.saludcapital.gov.co/sitios/VigilanciaSaludPublica/ Protocolos\%20de\%20Vigilancia\%20en\%20Salud\%20Publica/Funerarias\%20 Cementerios\%20y\%20Hornos.pdf

Strauss, Anselm L.; Corbin Juliet (2002). Bases de la investigación cualitativa. Técnicas y procedimientos para desarrollar la teoría fundamentada. Medellín: Universidad de Antioquia.

Thomas, Louis-Vincent (1985). Rites de mort. Pour la paix des vivants. París: Fayard.

Thomas, Louis-Vincent (1989). El cadáver: de la biología a la antropología. México: FCE.

Tschannen, Oliver (1992). Les théories de la sécularisation. Ginebra: Droz.

Unidad Administrativa Especial Servicios Públicos (2012). Cartilla proyecto de inversión 583 “Gestión para los servicios funerarios distritales”. Recuperado de http://www.uaesp.gov. co/uaesp_jo/images/planeacion/FORMULACION\%20DE\%20PROYECTOS/583 FORMULACION_PROYECTO_BH.pdf 
Villa-Posse, Eugenia (1993). Muerte, cultos y cementerios. Bogotá: Disloque.

Villa-Posse, Eugenia (2002). Creencias y prácticas del morir, cambios en los ritos fúnebres de la vida contemporánea. Credencial historia, 155, 10-12. Recuperado de https://www. banrepcultural.org/biblioteca-virtual/credencial-historia/numero-155/creencias-ypracticas-del-morir

Weber, Max (2014). Economía y sociedad. México: FCE. 